\title{
Cooperation and the Pricing Strategy in Dual Channel Based on the Earnings Management
}

\author{
Yongxiang $\mathrm{Li}^{1}$ and Dandan $\mathrm{Yao}^{2}$ \\ ${ }^{1}$ Hunan Industry Polytechnic (China) \\ Hunan Industry Polytechnic, Changsha, 410208, China \\ '280241744@qq.com, ${ }^{2} 125835952 @ q q . c o m$
}

\begin{abstract}
This paper researches the inventory problem and sales conflict in dual channel. The two basic problems are the basic problems of manufacturers or retailers have to face to establish network channel. We discuss that the network sales channels should establish their own inventory, or share the inventory with the physical store for inventory problem; we use dynamic pricing strategy to analyze and solve the problems of channel conflict for the conflict problem of Internet channel and physical channel. We studied the problem of inventory on the basis whether the network sales channels should establish their own inventory in dual channel. And then we analyzed the dynamic pricing model. The first part of this paper is the introduction of related problems and study of issues progress now. The second part is related assumptions and description the model analysis. In this part we describe the inventory strategy and dynamic pricing problem respectively. The third part is the numerical test. At the last of paper is the conclusion.
\end{abstract}

Keywords: Dual channel, Channel cooperation, pricing Strategy

\section{Introduction}

With the development of Internet, great changes have taken place in the consumer shopping behaviors. Consumers within doors will be able to purchase the goods by $7 \times 24 \mathrm{~h}$ network online mode. More and more retailers began to use electronic commerce to sell to consumers in order to meet the new demands of consumers. The advantages of traditional channels are close to consumers, consumers can obtain more consumption experience, directly contact the product and try and immediate payment products. In contrast, the network channel has the advantage of being able to provide more timely information, reducing consumers' search costs, while providing more extensive product selection. But the corresponding, network sales channels will have a negative impact on the traditional channels. This paper attempts to explore the method to solve this kind of channel conflict in order to minimize the loss and maximize the retailer's revenue.

The conflict of dual channel has attracted the attention of many scholars. Eppen and Tagaras researched the inventory transportation and distribution problems of dual channel [12]. Zhao and Cao considered the influence of inventory strategy of two cycles in dual channel supply chain on its pricing and profit, the research shows that the price of the products in electronic retailers with zero inventory is lower than the price of retailers own its own inventory, tut the price difference will decrease with time in rapid expansion market [3]. Considering the mixed double channel composed of a retailers with traditional retail channel and manufacturers have online channel. Manufacturers and retailers manage their inventory respectively, when the products are absent, the customers will transfer to another channel to 
buy goods in a certain percentage [4]. Boycai studied the distribution system of dual channel conditions and discuss the impact on channel efficiency of channel order quantity decision problem and the ratio of substitution [5]. Geng and Mallik discussed the inventory competition and double channel assignment problem and proposed the game equilibrium of the conditions manufacturers' capacity are not limited and limited .Study found that even in capacity limited circumstances, manufacturers may also refuse to the retailer orders [6]. Benoly researched on a large amount of stock can replace the situation by means of simulation [7]. Chen evaluates two kinds of inventory strategy of online retailers with Mathematical experiments [8]. Yeoman, et al., studies the revenue maximizing in dynamic pricing problem [9]. Veinott researched multi type demand in a single product, multi period, and non-stationary inventory environment [10]. Gerchak, et al., discussed a perishable product at a certain finite time range has the situation of two different customer group in the initial inventory given situation and the goal is to get the optimal order fulfillment strategies [11]. Gerchak, et al., extended the model of each customer only to buy a product [12]. Banerjee and Viswanathan considered the volume of demand [13]. Frank, et al., studied on inventory system has different priority requirement types in a cycle: the deterministic demand and stochastic demand. The level of deterministic demand optimization is high and the random demand is low. And the Decision makers can select random customer rationing inventory [14]. Frank Y. Chen applied the model of Gerchak [12] to discuss the selection problem of network retail sales channels and expanded it [15.] Yongbo Xiao discussed two subjects and each subject has four different customer group situations on the basis of the model of Frank [16]. Frank studied two subjects on the basis of this models, each subject has two different customer group situations [17].Dynamic pricing model of single product originally developed by Kincaid and Darling kernel study. They established a continuous time stochastic dynamic process and researched the payoff function [18]. Kunreuther and Schrage proved the price can be changed in a short time, and the price change in reality is more and more popular through the actual research [19]. Bitran studied on the relations between dynamic pricing and revenue management, conclude the existing literature and pointed out that the ultimate purpose of income management is to maximize the total revenue [20]. Elmaghraby concluded the revenue management pricing for the two aspects: posted price mechanisms and price discovery mechanisms [21]. Gallego and van Ryzin combine the strength control system theory and perishable products dynamic pricing problem and explain the traditional revenue management with dynamic pricing in a creative way. The results of their research is also called GVR model, and made a very important foundation for the future to continue studying [22]. After that, Gallego and van Ryzin applied the problem of the dynamic pricing from a single product to multi products. They assume that the demand process is a Poisson process, and multi product dynamic pricing problem is formulated as a strength control problem, the famous Hamilton-Jacobi-Bellman equation is derived [23]. Zhang and Cooper researched special problems of parallel flight in multi -product and multiresource dynamic pricing problem and structure this problem as a Markov decision process [24]. Gabriel Bitran and Rene Caldentey studied the revenue management problem in a new angle [25].

\section{Model Analysis}

\subsection{Model Assumptions and Description}

The business of reality is simplified, we consider the following scenario: a retailer, who has a physical store of seasonal products and running his own shop in order to attract more customers. Network shop and entity shop sales the same seasonal products. The price of the 
entity shop is $p_{2}$. The price of entity shop is stable at a specific period. We assume that the price of entity shop is fixed in the sales cycle $T$. It is reasonable to consider the short sales cycle and the cost and convenience factors of pricing and changing the label in a sales cycle .Assume that the price of this product in network sales is $p_{1}$ and it is changeable. It is easy to change the price of the product in network sale with the help of related software and we can affect the needs of shop needs and entity shop though changing the price of network sale channel. So we can make the total revenue vendors to maximize with the coordination between this two

Online pricing can be less than that of entity shop. The reason may be this are more inventory which is greater than demand of entity shop, namely oversupply. So the network shop attracts more customers to digest inventory through a slightly lower price. Online pricing can be higher than that of entity shop. The reason may be this are less inventory which is lower than demand of entity shop, namely demand exceeds supply. Therefore the shop high priced to reduce lower income customers and increase the high income customers by the slightly higher prices. The two conditions are symmetrical, and second cases are few applied in reality, this is because of the characteristic of the shop channels and entity shop. So this paper only consider the online pricing is less than or equal to the entity shop prices, which is the most common situation in real life channel i.e., $0 \leq p_{1} \leq p_{2}$.

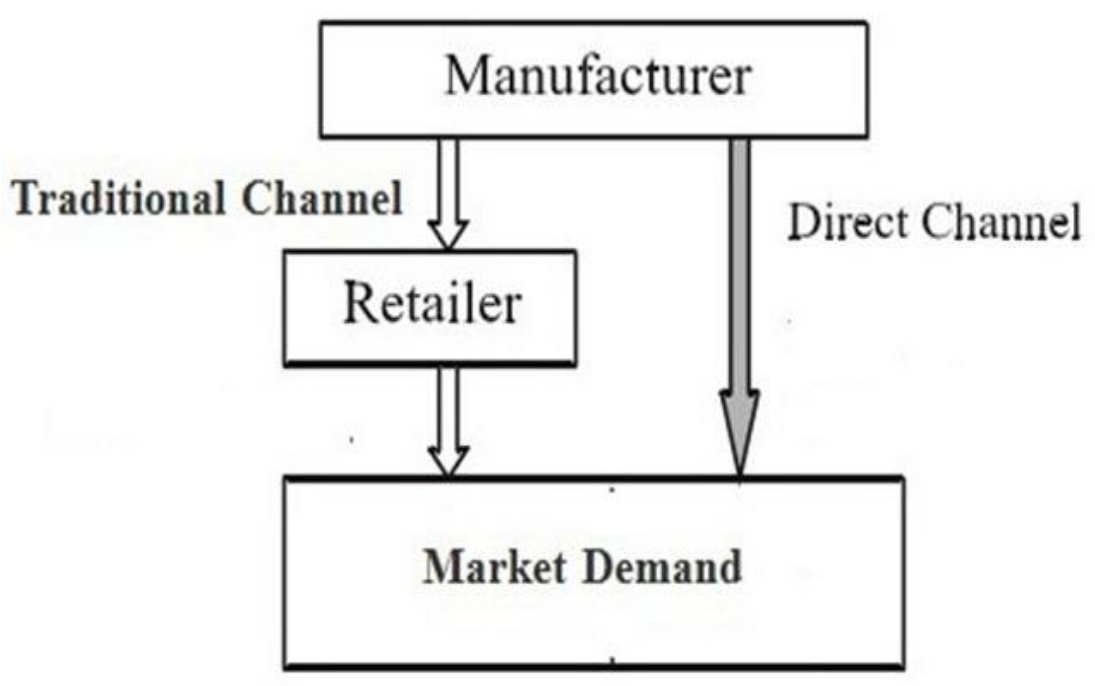

Figure 1. The Dual Channel

Because the price of network shop level will not only reverse influence customer to network shop on the product demand, but also will produce the effect on the entity shop needs. Similarly, prices of entity shop affect the demand of network shop. The higher the price of network shop, shops' demand decreases and the demand of entity shop will increase; the lower the price of network shop, shops' demand increases and the demand of entity shop will decrease. We represent $\lambda_{1}\left(p_{1}\right)$ and $\lambda_{2}\left(p_{2}\right)$ as customer arrival rate of network shop and entities shop respectively. Suppose that a customer only buys a product and the arrival of two customers is independent of each other. We can use below equations to express the relationship between the arrival rate and pricing:

$$
\begin{gathered}
\lambda_{1}\left(p_{1}\right)=A_{1}-B_{1} p_{1}, A_{1}>0, B_{1}>0 ; \\
\lambda_{2}\left(p_{1}\right)=A_{2}-B_{2} p_{1}, A_{2}>0, B_{2}>0 ;
\end{gathered}
$$


Hypothesis:

Hypothesis 1: $B_{1}>B_{2}$ namely the effect of the price of network shop on its demand is bigger than that on the demand of entity shop. This is obviously, because the network shop is equivalent to the substitutes of the entity shop.

Hypothesis 2: $A_{1} / B_{1}>p_{2}$, namely the price of the network shop is the same with the price of entity shop, the network shop also have certain requirements. When the price is higher than or equal to $A_{1} / B_{1}$, the demand of the network shop is zero.

In addition, the products the retailers sell are seasonal products and the sales period is finite and certain. There don't allow replenishment in the period of sales. We divide the sell period into several equal intervals $\Delta t$ for the convenience of analysis and not loss generality. Every $\Delta t$ is a stage and is very small. So the probability of appearing two or more than two customer arrivals is zero in a stage, i.e. there is only one or zero customer arrivals in every $\Delta t$. The whole sales cycle is $[0, T]$ and $\Delta t=1, t=1,2, \cdots, T$.

Because the customer arrival obeys the Poisson distribution, the rate of customer arrival is equal to the expected number of the customer arrival in $\Delta t . \lambda_{1}\left(p_{1}\right) / T$ is equal to the number of the exception customer Garrival in network shop in $\Delta t$ with the network customers arrivals as an example:

$$
\lambda_{1}\left(p_{1}\right) / T=1 P(1)+2 P(2)+3 P(3)+\cdots
$$

As the probability of the occurrence of two or more customer arrivals can be ignored, $\lambda_{1}\left(p_{1}\right) / T=1 p(1)$. We set $\lambda_{1}\left(p_{1}\right) / T=\lambda_{1}$, namely the probability of one customer arrives in network shop is equal to the expected value of Poisson distribution. The probability of one customer arrives in entity shop is equal to $\lambda_{1}\left(p_{1}\right) / T$ in by analogy $\Delta t$, we set as $\lambda_{2}$. The probability of none customer arrives is $1-\lambda_{1}-\lambda_{2}$. We can get $0<\lambda_{1}+\lambda_{2}<1$, and:

$$
\begin{aligned}
& \lambda_{1}=\frac{A_{1}}{T}-\frac{B_{1}}{T} p_{1}=a_{1}-b_{1} p_{1}, a_{1}>0, b_{1}>0 \\
& \lambda_{2}=\frac{A_{2}}{T}-\frac{B_{2}}{T} p_{1}=a_{2}-b_{2} p_{1}, a_{2}>0, b_{2}>0
\end{aligned}
$$

We can get two problems retailers need to solve:

(1)Do the channel of network and entity shop share a network inventory or set up their inventories respectively? The first condition is the network shop and entity shop build inventory respectively, when the network shop is out of stock, it can get products from the inventory of entity shop to the destination. The network shop inventory can't deliver products to the entity shop because the sale of entity shop is time-efficient. This means if there is no product when customer arrive the entity shop, they won't wait and leave i.e., the model of loss sale. The second condition is two channels share an inventory and this inventory supply products for network shop and entity shop at the same time. This method can decrease the uncertainty the change of demand brings namely effect of inventory polling. So Enterprises need to make a balance between the two and decide to choose which stock strategy.

(2) How the network channels made the strategy of dynamic pricing to minimize the conflict with entity shop sales and maximize the profits of retailers. This is the problem of dynamic pricing 


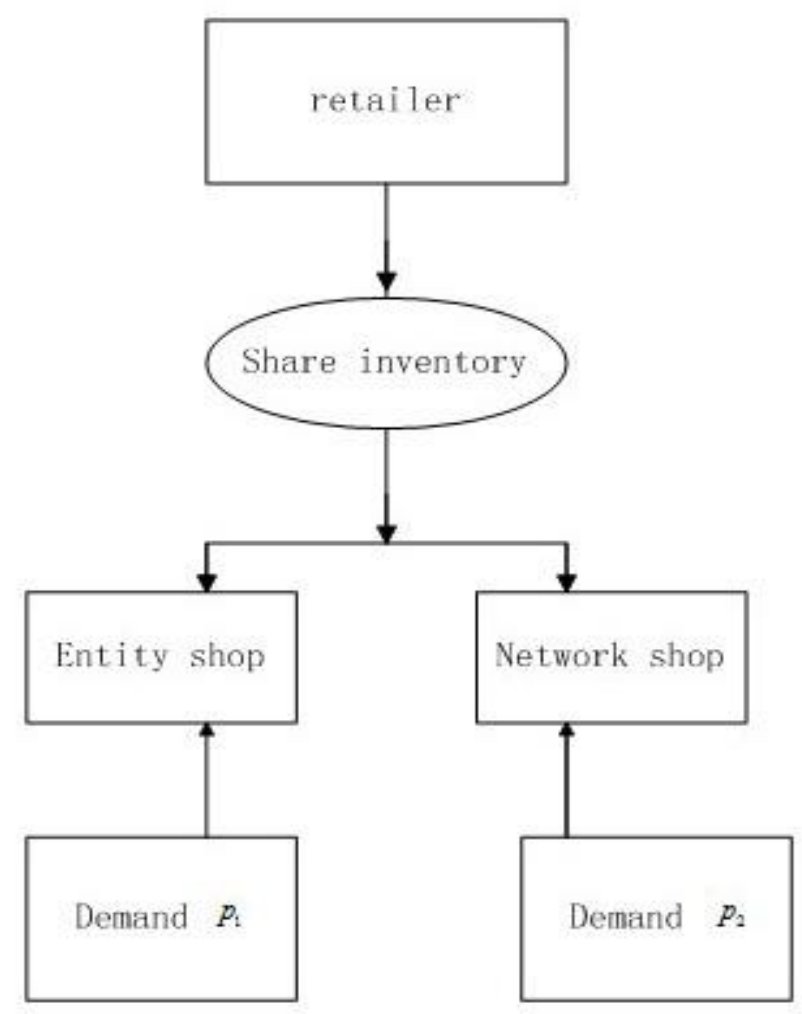

Figure 2. Share Inventory

\subsection{Optimal Dynamic Pricing}

We Using a three dimensional vector $\left(t, n_{1}, n_{2}\right)$ to describe the entire sales system state, $t$ is current time belong to $[0, T], n_{1}, n_{2}$ is the inventory level of network shop and entity shop. $\left(n_{1}, n_{2}\right)$ is the system state in the first condition and we set the system state is $R_{t}\left(n_{2}\right) \cdot R_{t}\left(n_{2}\right)$ is the total maximum expected future income in sale cycle $[t, T]$ from $t$ to the end when inventory level in entity shop is $n_{2}$.And we can get the recursive dynamic process. In second condition we use three dimensional vectors $\left(t, n_{1}, n_{2}\right)$ to describe the sales system state. We set $R_{t}\left(n_{1}, n_{2}\right)$ is the total maximum expected future income in sale cycle $[t, T]$ from $t$ to the end when inventory level in entity shop is $n_{2}$ and the inventory level in network shop is $n_{1}$. Similar we can get the recursive dynamic process.

In addition, because the store inventory is not specifically designed for the demand of network shop to provide order fulfillment, it is just the temporary supplement for network shop in the second case, so we set a specific cost to perform network order: $d$.

At last, we assume procurement cost in two channels is the same: $c$ to analysis the initial inventory optimal in two cases as network channel and physical channel belong to one seller.

The profit functions $R_{t}\left(n_{2}\right)$ and $R_{t}\left(n_{1}, n_{2}\right)$ is the decreasing function about time $t$ and is a increase function about surplus stock $n$.

Theorem 1: The profit function $R_{t}\left(n_{2}\right)$ possesses characteristics:

(1) $R_{t}\left(n_{2}\right)$ increases with the increase of $n_{2}$ and decreases with the increase of $t$;

(2) $R_{t}\left(n_{2}\right)-R_{t}\left(n_{2}-1\right)$ decreases with the increase of $n_{2}$ and decreases with the increase of $t$

Theorem 2: The profit function $R_{t}\left(n_{1}, n_{2}\right)$ possesses characteristics: 
(1) $R_{t}\left(n_{2}\right)$ increases with the increase of $n_{1}, n_{2}$ and decreases with the increase of $t$;

(2) $R_{t}\left(n_{1}+1, n_{2}\right)-R_{t}\left(n_{1}, n_{2}\right)$ decreases with the increase of $n_{1}, n_{2}$;

(3) $R_{t}\left(n_{1}, n_{2}+1\right)-R_{t}\left(n_{1}, n_{2}\right)$ decreases with the increase of $n_{1}, n_{2}$;

(4) $R_{t}\left(n_{1}+1, n_{2}\right)-R_{t}\left(n_{1}, n_{2}+1\right)$ decreases with the increase of $n_{1}$ and increases with the increase of $n_{2}$;

(5) $R_{t+1}\left(n_{1} n_{2}\right)-R_{t}\left(n_{1}, n_{2}\right)$ decreases with the increase of $n_{1}, n_{2}$ and decreases with the increase of $t$;

\subsubsection{The first condition}

The maximum future expectation income of retailer in $t$ stage is:

$$
\begin{gathered}
R_{t}\left(n_{2}\right)=\max _{p_{1}}\left\{\lambda_{1}\left[p_{1}+R_{t+1}\left(n_{2}-1\right)\right]+\lambda_{2}\left[p_{2}+R_{t+1}\left(n_{2}-1\right)\right]+\left(1-\lambda_{1}-\lambda_{2}\right) R_{t+1}\left(n_{2}\right)\right\} \\
R_{t}(0)=0, R_{T+1}(n)=0
\end{gathered}
$$

Put the type (1), (2) into type (3) we get:

$$
\begin{aligned}
& R_{t}\left(n_{2}\right)=\max _{p_{1}}\left\{\left(a_{1}-b_{1} p_{1}\right)\left[p_{1}+R_{t+1}\left(n_{2}-1\right)\right]+\left(a_{2}-b_{2} p_{1}\right)\left[p_{2}+R_{t+1}\left(n_{2}-1\right)\right]\right. \\
& \left.+\left[1-a_{1}-a_{2}+\left(b_{1}-b_{2}\right) p_{1}\right] R_{t+1}\left(n_{2}\right)\right\} \\
& \Rightarrow \frac{d R_{t}\left(n_{2}\right)}{d p_{1}}=\left[a_{1}-b_{1} R_{t+1}\left(n_{2}-1\right)\right]-2 b_{1} p_{1}+b_{2}\left[p_{2}+R_{t+1}\left(n_{2}-1\right)\right]+\left(b_{1}-b_{2}\right) R_{t+1}\left(n_{2}\right)=0 \\
& \frac{d^{2} R_{t}\left(n_{2}\right)}{d p_{1}{ }^{2}}=-2 b_{1}<0 \Rightarrow p_{1 t}^{*}\left(n_{2}\right)= \\
& \frac{a_{1}+b_{2} p_{2}\left(b_{1}-b_{2}\right)\left[R_{t+1}\left(n_{2}\right)-R_{t+1}\left(n_{2}-1\right)\right]}{2 b_{1}}
\end{aligned}
$$

We can infer the first case related conclusions through analyzing the structural features of the profit function from the optimal dynamic pricing as follows:

Conclusion 1: Optimal dynamic pricing: $p_{1 t}^{*}\left(n_{2}\right)$ is a series of price lists and increases with the decrease of $n_{2}$ and decreases with the increase of $t$;

Conclusion 2: The relationship between the optimal dynamic pricing: $p_{1 t}^{*}\left(n_{2}\right)$ and the coefficient is: the optimal dynamic pricing: $p_{1 t}^{*}\left(n_{2}\right)$ increases with the increase of $a_{1}$, decreases with the increase of $b_{1}$ and increases with the increase of $b_{2}$;

Conclusion 3: Optimal dynamic pricing is larger than the optimal static pricing static process: $p_{1}$ is fixed, so the whole process is given without the dynamic recursive process. And we can the $p_{1}$ which maximize the profit:

$$
\begin{aligned}
& \max _{p_{1}}\left\{R_{1}(Q)\right\}=\lambda_{1} p_{1}+\lambda_{2} p_{2}=\left(A_{1}-B_{1} p_{1}\right) p_{1}+\left(A_{2}-B_{2} p_{1}\right) p_{2} \\
& \Rightarrow p_{1}^{\#}=\frac{A_{1}+B_{2} p_{2}}{2 B_{1}}=\frac{a_{1}+b_{2} p_{2}}{2 b_{1}}
\end{aligned}
$$

Dynamic pricing: every state $\left(t, n_{2}\right)$ corresponds one optimal pricing. The rang of $R_{t}\left(n_{2}\right)-R_{t}\left(n_{2}-1\right)$ is $\left[0, p_{2}\right]$, we infer:

$$
\begin{aligned}
& \frac{a_{1}+b_{2} p_{2}}{2 b_{1}} \leq p_{1 t}^{*}\left(n_{2}\right) \\
& =\frac{a_{1}+b_{2} p_{2}+\left(b_{1}-b_{2}\right)\left[R_{t+1}\left(n_{2}\right)-R_{t+1}\left(n_{2}-1\right)\right]}{2 b_{1}} \leq \frac{a_{1}+b_{1} p_{2}}{2 b_{1}}
\end{aligned}
$$


Optimal dynamic pricing is larger than the optimal dynamic pricing. We can get the following constraints as the rang of $p_{1}$ and guarantee the optimal solution:

$$
\frac{a_{1}+b_{2} p_{2}}{2 b_{1}} \leq p_{2}
$$

So

\subsubsection{The Second Condition}

$$
\frac{a_{1}+b_{2} p_{2}}{2 p_{1}} \leq b_{1} \leq \frac{a_{1}}{p_{2}}
$$

The network shop and the entity shop won their inventory respectively. If there is no product in the network shop, we allow the entity shop to perform network order, But if there is no product in the entity shop, thy loss the customers.

The total maximum expected future profits of retailer are discussed as follows:

$$
\begin{aligned}
& R_{t}\left(n_{1}, n_{2}\right)= \\
& \left\{\begin{array}{l}
0,\left(n_{1}=0, n_{2}=0\right) \\
\max \left\{\lambda_{1}\left[p_{1}+R_{t+1}(n-1,0)\right]+\left(1-\lambda_{1}\right) R_{t+1}\right.
\end{array}\right. \\
& \left.\left(n_{1}, 0\right)\right\},\left(n_{1}>0, n_{2}=0\right) \\
& \max _{p_{1}}\left\{\lambda_{1}\left[p_{1}-d+R_{t+1}\left(0, n_{2}-1\right)\right]+\lambda_{2}\left[p_{2}+\right.\right. \\
& \left.\left.R_{t+1}\left(0, n_{2}-1\right)\right]+\left(1-\lambda_{1}-\lambda_{2}\right) R_{t+1}\left(0 . n_{2}\right)\right\}, \\
& \left(n_{1}=0, n_{2}>0\right) \\
& \max _{p_{1}}\left\{\lambda_{1}\left[p_{1}+R_{t+1}\left(n_{1}-1, n_{2}\right)\right]+\lambda_{2}\left[p_{2}+\right.\right. \\
& \left.\left.R_{t+1}\left(n_{1}, n_{2}-1\right)\right]+\left(1-\lambda_{1}-\lambda_{2}\right) R_{t+1}\left(n_{1}, n_{2}\right)\right\}, \\
& \left(n_{1}>0, n_{2}>0\right)
\end{aligned}
$$

$R_{t}(0,0)=0, R_{T+1}\left(n_{1}, n_{2}\right)=0$.put the type (1) and (2) into type (6), get:

(1)When $n_{1}>0, n_{2}=0$

$$
\begin{aligned}
& R_{t}\left(n_{1}\right)=\max \left\{\left(a_{1}-b_{1} p_{1}\right)\left[p_{1}+R_{t+1}\left(n_{1}-1\right)\right]\right. \\
& \left.+\left[1-a_{1}+b_{1} p_{1}\right] R_{t+1}\left(n_{1}\right)\right\} \\
& \Rightarrow \frac{d R_{t}\left(n_{1}\right)}{d p_{1}}=\left[a_{1}-b_{1} R_{t+1}\left(n_{1}-1\right)\right]-2 b_{1} p_{1}+ \\
& b_{1} R_{t+1}\left(n_{1}\right)=0 \\
& \frac{d^{2} R_{t}\left(n_{1}\right)}{d p_{1}{ }^{2}}=-2 b_{1}<0 \\
& \Rightarrow p_{1 t}^{*}\left(n_{1}\right)=\frac{a_{1}+b_{1}\left[R_{t+1}\left(n_{1}\right)-R_{t+1}\left(n_{1}-1\right)\right]}{2 b_{1}}
\end{aligned}
$$

As $b_{1}>0$, so the optimal pricing is proportional to $R_{t+1}\left(n_{1}\right)-R_{t+1}\left(n_{1}-1\right)$. We can get the optimal dynamic pricing $p_{1 t}^{*}\left(n_{1}\right)$ is a series of price lists and increases with the decrease of $n_{1}$, decreases with the increase of $t$ from the theorem 2 .

(2)When $n_{1}=0, n_{2}>0$ 


$$
\begin{aligned}
& R_{t}\left(n_{2}\right)=\max \left\{\left(a_{1}-b_{1} p_{1}\right)\left[p_{1}-d+R_{t+1}\left(n_{2}-1\right)\right]\right. \\
& +\left(a_{2}+b_{2} p_{1}\right)\left[p_{2}+R_{t+1}\left(n_{2}-1\right)\right]+\left[1-a_{1}-a_{2}+\right. \\
& \left.\left.\left(b_{1}-b_{2}\right) p_{1}\right] R_{t+1}\left(n_{2}\right)\right\} \\
& \left.\Rightarrow \frac{d R_{t}\left(n_{2}\right)}{d p_{1}}=a_{1}-b_{1} R_{t+1}\left(n_{2}-1\right)\right]+b_{1} d-2 b_{1} p_{1}+ \\
& b_{2} R_{t+1}\left(n_{2}-1\right)+\left(b_{1}-b_{2}\right) R_{t+1}\left(n_{2}\right)=0 \\
& \frac{d^{2} R_{t}\left(n_{2}\right)}{d p_{1}^{2}}=-2 b_{1}<0 \\
& \Rightarrow p_{1 t}^{*}\left(n_{2}\right)=\frac{a_{1}+b_{2} p_{2}+b_{1} d+\left(b_{1}-b_{2}\right)\left[R_{t+1}\left(n_{2}\right)-R_{t+1}\left(n_{2}-1\right)\right]}{2 b_{1}}
\end{aligned}
$$

As $b_{1}>b_{2}$, so the optimal pricing is proportional to $R_{t+1}\left(n_{2}\right)-R_{t+1}\left(n_{2}-1\right)$. We can get the optimal dynamic pricing $p_{1 t}^{*}\left(n_{2}\right)$ is a series of price lists and increases with the decrease of $n_{2}$, decreases with the increase of $t$ from the theorem 2 .

(3) When $n_{1}>0, n_{2}>0$

$$
\begin{aligned}
& R_{t}\left(n_{1}, n_{2}\right)=\max _{p_{1}}\left\{\left(a_{1}-b_{1} p_{1}\right)\left[p_{1}+R_{t+1}\left(n_{1}-1, n_{2}\right)\right]\right. \\
& +\left(a_{2}+b_{2} p_{1}\right)\left[p_{2}+R_{t+1}\left(n_{1}, n_{2}-1\right)\right]+\left[1-a_{1}-a_{2}+\right. \\
& \left.\left.\left(b_{1}-b_{2}\right) p_{1}\right] R_{t+1}\left(n_{1}, n_{2}\right)\right\} \\
& \left.\Rightarrow \frac{d R_{t}\left(n_{1}, n_{2}\right)}{d p_{1}}=a_{1}-b_{1} R_{t+1}\left(n_{1}-1, n_{2}\right)\right]-2 b_{1} p_{1}+b_{2} p_{2} \\
& b_{2} R_{t+1}\left(n_{1}, n_{2}-1\right)+\left(b_{1}-b_{2}\right) R_{t+1}\left(n_{1}, n_{2}\right)=0 \\
& \frac{d^{2} R_{t}\left(n_{2}\right)}{d p_{1}^{2}}=-2 b_{1}<0
\end{aligned}
$$

And

$$
\begin{aligned}
& p_{1 t}^{*}\left(n_{1}, n_{2}\right)=\frac{a_{1}+b_{2} p_{2}+b_{1}\left[R_{t+1}\left(n_{1}, n_{2}\right)-R_{t+1}\left(n_{1}-1, n_{2}\right)\right]}{2 b_{1}} \\
& -\frac{b_{2}\left[R_{t+1}\left(n_{1}, n_{2}\right)-R_{t+1}\left(n_{1}, n_{2}-1\right)\right]}{2 b_{1}} \\
& =\frac{a_{1}+b_{2} p_{2}+\left(b_{1}-b_{2}\right) R_{t+1}\left(n_{1}, n_{2}\right)}{2 b_{1}} \\
& +\frac{-b_{1} R_{t+1}\left(n_{1}-1, n_{2}\right)+b_{2} R_{t+1}\left(n_{1}, n_{2}-1\right)}{2 b_{1}} \\
& =\frac{a_{1}+b_{2} p_{2}+\left(b_{1}-b_{2}\right)\left[R_{t+1}\left(n_{1}, n_{2}\right)-R_{t+1}\left(n_{1}-1, n_{2}\right)\right]}{2 b_{1}} \\
& +\frac{b_{2} p_{2}\left[R_{t+1}\left(n_{1}, n_{2}-1\right)-R_{t+1}\left(n_{1}-1, n_{2}\right)\right]}{2 b_{1}}
\end{aligned}
$$

We can get the optimal dynamic pricing $p_{1 t}^{*}\left(n_{1}, n_{2}\right)$ is a series of price lists and increases with the decrease of $n_{1}$, decreases with the increase of $t$ from the theorem 2.

\section{Numerical Experiment}

\subsection{The Discussion of the Inventory Strategy}

Firstly, we need discuss the profits of which inventory strategy is larger, the network shop and the entity shop share the inventory or build their inventory respectively? 
We assume that the customer arrivals of two channels are the same and the total inventory is the same too. $T=100$, the initial inventory is $Q_{2}=200$, the price of the entity shop is $p_{2}=50$, the price of the network shop is $p_{1}$ and it is dynamic adjustment , $a_{1}=80 / T, a_{2}=30 / T$ $b_{1}=4 / T, b_{2}=2 / T, d=2 / T$.

Table 1. The Comparison of Profits

\begin{tabular}{|l|l|l|l|l|l|}
\hline & \multicolumn{2}{|c|}{ Share inventory } & & \multicolumn{2}{c|}{ build inventory respectively } \\
\hline & $n_{2}$ & Profits & $n_{1}$ & $n_{2}$ & Profits \\
\hline 1 & 200 & 3431.7 & 180 & 20 & 2986.7 \\
\hline 2 & 200 & 3431.7 & 170 & 30 & 3015.4 \\
\hline 3 & 200 & 3431.7 & 160 & 40 & 3189.5 \\
\hline 4 & 200 & 3431.7 & 140 & 60 & 3243.9 \\
\hline 5 & 200 & 3431.7 & 120 & 80 & 3367.8 \\
\hline 6 & 200 & 3431.7 & 100 & 100 & 3403.7 \\
\hline 7 & 200 & 3431.7 & 80 & 120 & 3428.6 \\
\hline 8 & 200 & 3431.7 & 60 & 140 & 3578.4 \\
\hline 9 & 200 & 3431.7 & 40 & 160 & 3476.3 \\
\hline 10 & 200 & 3431.7 & 0 & 200 & 3398.6 \\
\hline
\end{tabular}

From the above numerical results, we can see that the strategy of share inventory can get more profits than the strategy of build inventory respectively.

\subsection{The Comparison of Dynamic Pricing and Static Pricing}

We use the data of Experiment 1 and compare the profits of two different pricing models, the result is showed:

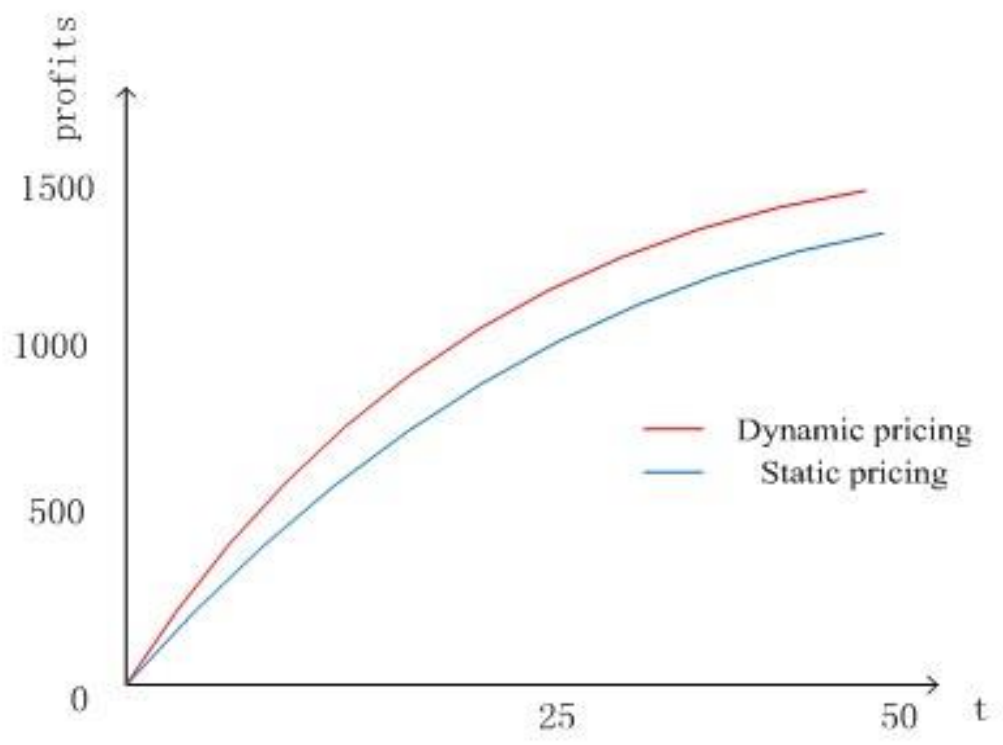

Figure 3. The Comparison of Dynamic Pricing and Static Pricing 
In this diagram we can see clearly that the profit of the dynamic pricing strategy is larger than the profit of static pricing strategy as time increases. Namely the difference between the two strategies is larger and larger. With the passage of time, the advantage of dynamic pricing strategy will gradually emerge.

Numerical results illustrate the conclusion 3 in this article, i.e., the profit of optimal dynamic pricing is larger than the profits of the optimal dynamic pricing and the result of the optimal dynamic pricing is better than the optimal static pricing.

\section{Conclusion}

This paper studies the inventory strategy and dynamic pricing strategy of retailer under the dual channel. Research shows that it is a better solution for the network shop and the entity shop share inventory. We consult the model of dynamic inventory rationing, analyzed dynamic optimal pricing model and the process according to the inventory level and time state. Numerical experiments show that the network shop and the entity shop share store inventory will get better profits and the dynamic pricing is better than the static pricing.

This paper studied the seasonal products and perishable products. An important feature of this kind of products is that they must be sold in a specific period of time otherwise out of season and out of date will make the value of the product to zero.

In reality, pricing is also a process of decline. The model and results of this paper also proved this point and describes the process of dynamic pricing, to prove that it is a series of price lists gradually decrease.

It is an attractive problem about the dual channel. And this problem will also be paid more and more attention with the development of electronic commerce. This will lead deeper analysis and research in the area

\section{References}

[1] G. D. Eppen, "Effects of centralization of expected costs in a multi-location newsboy problem", Management Science, vol. 25, no. 1, (1979), pp. 498-501.

[2] G. Tagaras, "Effects of pooling on the optimization and service levels of two-location inventory systems", IIE Transactions, vol. 21, (1989), pp. 250-257.

[3] H. Zhao, Y. Cao, "The role of e-tailer inventory policy on e-tailer pricing and profitability", Journal of Retailing, vol. 80, no.3, (2004), pp. 207-219.

[4] W. Chaing, G. E. Monahan, "Managing inventories in a two-echolon dual-channel supply chain", European Journal of Operation Research, vol. 162, no. 3, (2005), pp. 325-341.

[5] T. Boyaci, "Competitive stocking and coordination in a multi-ple-channel distribution system", IIE transactions, vol. 37, no. 3, (2005), pp. 407-527.

[6] Q. Geng, S. Mallik, "Inventory competition and allocation in a multi-channel distribution system", European Journal of Operation Research, vol. 182, no. 3, (2007), pp. 704-729.

[7] E. Bendoly, "Integrated inventory pooling for firms serving both on-line and store demand", Computer \& Operations Research, vol. 31, no. 9, (2004), pp. 1465-1480.

[8] F. Y. Chen, S. H. Hum, C. H. Sim, "On inventory strategies of online retailers", Journal of Systems Science and Systems Engineering, vol. 14, no. 1, (2005) pp. 52-72.

[9] I. Yeoman, A. Ingold and S. E. Kimes, "Yield management: Editorial introduction", Journal of the Operational Research Society, vol. 50, (1999), pp. 1083-1084.

[10] A. F. Veinott, Jr., "Optimal policy in a dynamic, single product, non-stationary inventory model with several demand classes", Operations Research, vol. 13, no. 5, (1965), pp. 761-778.

[11] Y. Gerchak, M. Parlar and T. K. M. Yee, "Optimal rationing policies and production quantities for products with several demand classes", Canadian Journal of Administration Science, vol. 2, (1985), pp. 161-176.

[12] Y. Gerchak, M. Parlar and T. K. M. Yee, "Optimal rationing policies and production quantities for products with several demand classes", Canadian Journal of Administration Science, vol. 2, (1985), pp. 161-176.

[13] P. K. Banerjee and B. Viswanathan, "On optimal rationing policies", Canadian Journal of Administrative Science, vol. 12, (1989), pp. 1-6. 
[14] K. C. Frank, R. Q. Zhang and I. Duenyas, "Optimal policies for inventory systems with priority demand classes”, Operations Research, vol. 51, no. 6, (2003), pp. 993-1002.

[15] F. Y. Chen, J. Chen and Y. Xiao, "Optimal admission policies for a retailer of seasonal products with dropshipping", IEEE International Conference on Robotics and Automation, (2007).

[16] Y. Xiao, F. Y. Chen and J. Chen, "Optimal inventory and dynamic admission policies for a retailer of seasonal products with affiliate programs and drop-shipping”, NRL, vol. 56, no. 4, (2009), pp. 300-317.

[17] F. Y. Chen, J. Chen, M. Parlar and Y. Xiao, "Optimal inventory and admission policies for drop-shipping retailers serving in-store and online customers", IIE Transactions, vol. 43, no. 5, (2011), pp. 332-347.

[18] W. M. Kineaid and D. Darling, "An inventory pricing problem", Journal of Mathematical Analysis and Applications, vol. 7, no. 2, (1963), pp. 183-208.

[19] H. Kunreuther and L. Schrage, "Joint pricing and inventory decisions for constant priced items", Management Science, vol. 19, no. 7, (1973), pp. 732--738.

[20] G. Bitran and C. Rene, "An overview of pricing models for revenue management", Management Science, vol. 46, no. 7, (2000), pp. 941-956.

[21] W. Elmaghraby and P. Keskinocak, "Dynamic pricing: Research overview, current practices and future directions", Management Science, vol. 49, no. 10, (2003), pp. 1287-1309.

[22] G. Gallego and G. V. Ryzin, "Optimal dynamic pricing of inventories with stochastic demand over finite horizons", Management Science, vol. 40, no. 8, (1994), pp. 999-1020.

[23] G. Gallego and G. V. Ryzin, "A multiproduct dynamic pricing problem and its applications to network yield management”, Operations Research, vol. 45, no. 1, (1997), pp. 24-41.

[24] D. Zhang and W. L. Cooper, "Pricing substitutable flight in airline revenue management", European Journal of Operational Research, vol. 197, no. 3, (2009), pp. 848-861.

[25] G. Bitran, R. Caldentey, "An overview of pricing models for revenue management", Manufacturing and Service Operations Management, vol. 5, no. 3, (2003), pp. 203-229.

\section{Authors}

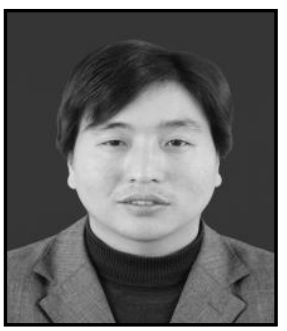

Yongxiang Li, Male, 1977-10, Shaoyang, Hunan, Han, Hunan Industry Polytechnic lecturer, logistics management professional full-time teachers, undergraduate degree, Bachelor of Science, Research direction: mainly engaged in logistics management, logistics technical and vocational education research.

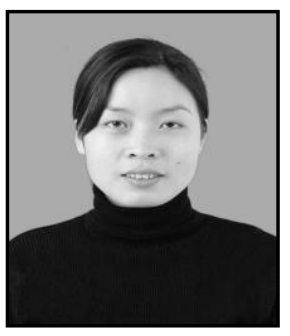

Dandan Yao, Female, 1983-6, Changde, Hunan, Han, Hunan Industry Polytechnic Institute of Management Studies lecturer, undergraduate degree, master's degree, research direction: mainly engaged in enterprise management and regional economic research 
International Journal of $u-$ and e- Service, Science and Technology Vol.7, No.3 (2014) 